International Journal of Homoeopathic Sciences 2021; 5(3): 05-08

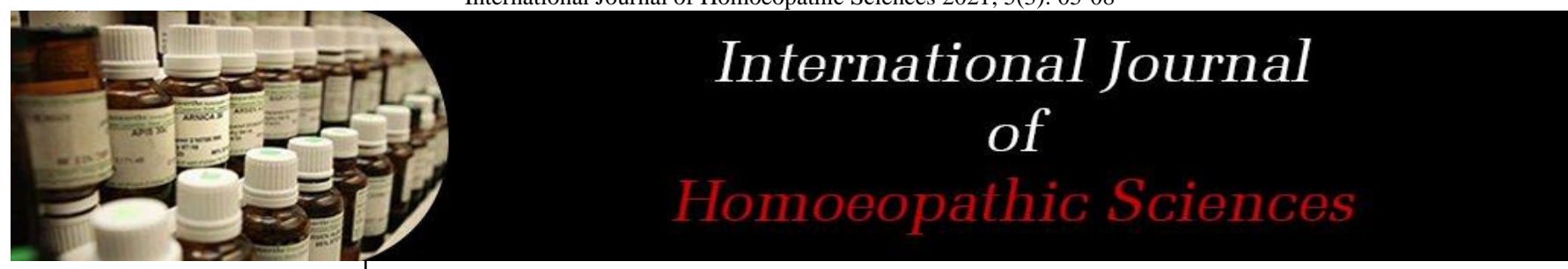

E-ISSN: 2616-4493 P-ISSN: 2616-4485 www.homoeopathicjournal.com IJHS 2021; 5(3): 05-08

Received: 04-05-2021

Accepted: 06-06-2021

\section{Dr. V Rekha}

Department of Physiology

MNR Homoeopathic Medical

College and Hospital,

Sangareddy, Hyderabad,

Telangana, India
Corresponding Author: Dr. V Rekha

Department of Physiology MNR Homoeopathic Medical

College and Hospital,

Sangareddy, Hyderabad,

Telangana, India

\title{
Homeopathic management of adenoids: A review
}

\section{Dr. V Rekha}

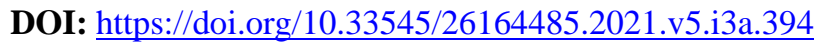

\section{Abstract}

Nasopharyngeal tonsil commonly called "Adenoids". "Adenoid" meaning "glandular", "gland-like", or "lymphatic". Hypertrophy of the lymphoid tissues in the throat (the adenoids) is the most common cause of nasal obstruction in children. The mouth is always open because upper airway congestion/narrowing has made patients obligatory mouth breathers. Persistent mouth breathing seen in children due to nasal obstruction can lead to malocclusion. The most common symptoms are habitual mouth breathing and snoring. The most dangerous symptom is sleep apnea due to obstruction. Homoeopathic medicines treat them effectively. These remedies aim to control the infection and inflammation in the initial phase and eliminate the risk of reoccurrence by improving the immunity in the later phase.

Keywords: adenoids, lymphoid tissue, nasopharyngeal tonsils, nasal obstruction, homoeopathic management

\section{Introduction}

Nasopharyngeal tonsil commonly called "Adenoids" is situated at the junction of the roof and posterior wall of the nasopharynx and is composed of vertical ridges of intestinal tissues. Adenoid tissue is present at birth, shows physiological enlargement up to the age of 6yrs ${ }^{[1]}$ due to heightened immunologic activity, often causing some airway obstruction ${ }^{[19]}$ and then tends to atrophy at puberty and almost completely disappears by the age of $20^{[1]}$.

Adenoids are tonsils, but not all tonsils are adenoids. The pharyngeal tonsils are commonly known as adenoids, according to Encyclopedia Britannica. They provide protection against infections and flush away unwanted particles. According to the American Academy of Otolaryngology, tonsils are the "first line of defense as part of the immune system." [8]

It differs from tonsillar tissue is that it contains no crypts, bounded by no capsule and is covered by ciliated epithelium ${ }^{[2]}$

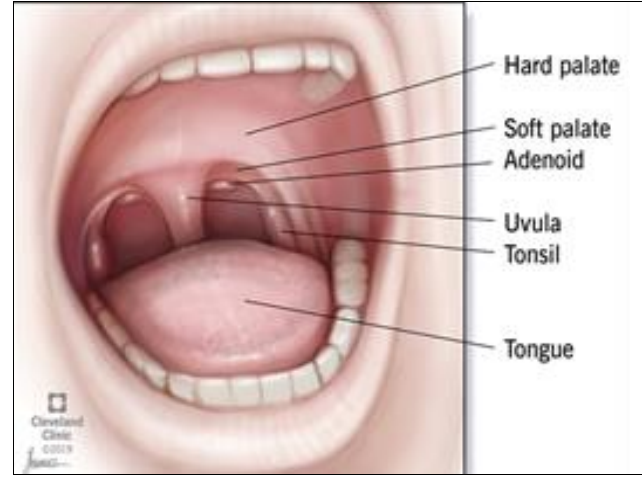

Fig 1: Adenoids located at the back of the mouth ${ }^{[5]}$

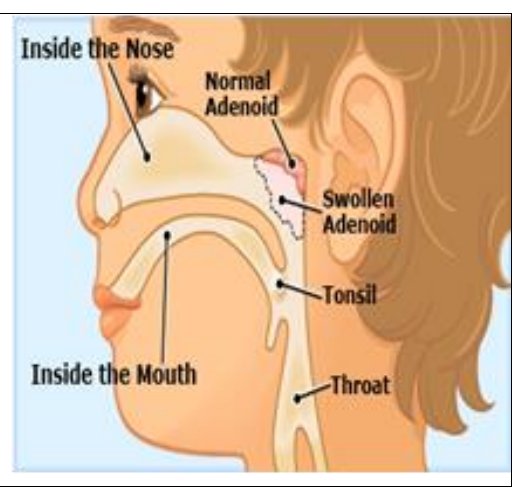

Fig 2: Enlarged Adenoid ${ }^{[6]}$ 
Differentiation between Tonsils and Adenoids ${ }^{[3]}$

\begin{tabular}{|c|c|c|}
\hline & Tonsils & Adenoids \\
\hline Number & Two & Single \\
\hline Site & Oropharynx & Nasopharynx \\
\hline Capsule & Present & Absent \\
\hline Floor or bed & Muscle (Superior constrictor) & Fascia covering basiocciput and sphenoid \\
\hline Surface & Crypts & Vertical ridges \\
\hline Lining & Stratified squamous epithelium & Ciliated \\
\hline $\begin{array}{l}\text { Postoperative } \\
\text { bleeding }\end{array}$ & $\begin{array}{l}\text { Easy to control because of muscular bed and } \\
\text { unilateral blood supply. }\end{array}$ & $\begin{array}{l}\text { Difficult as the bed is rigid and bilateral } \\
\text { blood supply. }\end{array}$ \\
\hline Blood supply & Unilateral chiefly facial artery & Bilateral \\
\hline Regression & Persists even after puberty & Regresses after the age of 12 yrs \\
\hline
\end{tabular}

When hypertrophied nasopharyngeal tonsils starts producing symptoms, the condition is referred to as adenoids. The normal involution of the nasopharyngeal tonsil starts from the onset of puberty, but sometimes it can persist for a longer period ${ }^{[4]}$.

\section{Predisposing Factors ${ }^{[4]}$ \\ Endogenous}

- Preexisting URTI

- Preexisting chronic tonsils

- Post nasal discharge due to sinusitis

- Residual tonsillar tissue after tonsillectomy

- General lowering of the resistance due diseases like agranulocytosis, leukemia

- Exanthemata

\section{Exogenous}

- Ingestion of cold drinks or cold foods may directly cause infection or lower the resistance by nasoconstriction

- Contagious - Infection may be contacted from other individuals having infection

- Pollution and crowded ill-ventilated environment

- Imbedded foreign body

\section{Clinical features}

Symptoms due to hypertrophy are produced not from the actual size of the lymphoid mass but from the relative disproportion in size between the adenoids and the cavity of the nasopharynx. This leads to nasal obstruction ${ }^{[2]}$.

1. In Infants: Interference with feeding because the baby has to stop sucking intermittently in order to take a breather. The infant tires easily, takes insufficient food and fails to thrive, Noisy respiration, wet bubbly nose [2].

2. In older children: Nasal obstruction leads to mouth breathing, Voice loses tone and become nasal and lifeless, Nasal discharge partly due to mechanical obstruction at the posterior nares and partly due to secondary chronic rhinitis, deafness due to the adenoid mass obstructing the openings of auditory tube. This diminishes the air entry into the middle ears ${ }^{[2]}$.

3. Adenoid facies ${ }^{[1]}$ : Chronic nasal obstruction and mouth breathing lead to characteristic facial appearance called adenoid facies. Child has elongated face, dull expression, open mouth, prominent and crowded upper tooth and hitched up upper lip. Nose gives a pinched appearance due to disuse atrophy of alae nasi. Hard palate is highly arched as the moulding action of the tongue on palate is lost.

4. Pulmonary hypertension
5. Aprosexia: Lack of concentration.

Symptoms due to infection ${ }^{[4]}$

1. Purulent discharge from the nose due to rhinitis and sinusitis may occur.

2. Epistaxis due to infection.

3. Throat - Recurrent URTI is frequent. Patient may have post nasal discharge, pharyngitis, tonsillitis and cough.

4. Ear - recurrent eustachian catarrh, acute otitis media, chronic otitis media may occur.

5. Lymphadenitis - Upper deep cervical node of the posterior triangle of neck is infected.

6. Bronchial asthma and bronchitis if present may get aggravated.

7. General - Nocturnal enuresis and night terrors may occur due to suffocation. Mental backwardness is not real, but the child may become backward in studies because of deafness.

\section{Diagnosis ${ }^{[4]}$}

1. Clinical features

2. Posterior rhinos copy

3. Digital palpation of the adenoids

4. Radiological examination of lateral view of nasopharynx for soft tissue shadow reveals adenoids

5. Examination under general anesthesia at the time of tonsillectomy.

\section{Differential diagnosis ${ }^{[4]}$}

1. Nasal obstruction: Other causes like rhinitis, sinusitis, antrochoanal polyp, DNS, hypertrophied turbinates and allergy.

2. Orthodontic abnormality: High arched palate with protruding teeth may also occur with obstruction.

3. In Thornwaldt's disease (Pharyngeal bursitis): Is a cyst in the midline of the nasopharynx in an adult which is thought to be the persistence of the median furrow of the adenoids, which is the attachment of the notochord to the endoderm of the primitive pharynx.

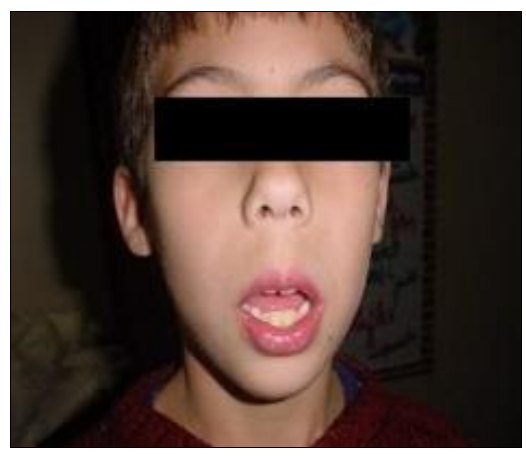

Fig 3: Adenoid facies ${ }^{[7]}$ 


\section{Treatment ${ }^{[4]}$}

Conservative: In mild cases conservative treatment may take care of adenoids. This is complemented by natural involution, antibiotics, decongestants, breathing exercises, general improvement in health and hygiene may help.

Surgical: Adenoidectomy (for persistent recurrence), Antral lavage (for concurrent sinusitis), Grommet (for pt. having secretory otitis media)

\section{Homoeopathic point of view}

Homeopathic medicines not only cure the infection but also help in improving the immunity of the child. This helps the child in fighting all sorts of infections and allows the child to grow properly. Homeopathic medicines attack the problem at the root, provide symptomatic relief and in time, shrink and remove adenoids. The true simillimum is always based on the existing miasm. It makes the difference between fighting the disease in the dark and in bright light when one knows the underlying principle that fathers the phenomena. If one has no knowledge of the laws of action and reaction, how can we watch the progress of a case without a definite knowledge of the disease forces (miasms) with their mysterious and persistent progressions? So, if we know nothing about the traits and characteristics of our enemy, it's impossible to wage a war against the disease.

In aphorism 78 Hahnemann said, "The true natural chronic diseases are those that arise from a chronic miasm, when left to themselves, improper treatment, go on to increase, growing worse and torment the patient to the end of his life." ${ }^{[20]}$ Hahnemann wrote about these things in his Theory of Chronic Disease: The physician skilled in anti-miasmatic prescribing dips deeper into the case and applies an agent that has a deeper and closer relationship with the perverted life force. The results are always better ${ }^{[21]}$.

Therefore it is highly recommended to retain the adenoids as they provide protection against infection and flush away unwanted particles.

\section{Therapeutics of Adenoids \\ Tuberculinum}

Enlarged Tonsils and adenoids. Hawks mucus after eating. All gone hungry sensation. Desire for delicacies, meat esp. smoked meat, refreshing things, salty things. Fear of animals especially dogs. Irritability on waking. Wants to fight, throws anything at anyone, doesn't want to remain in one place long. Desire to break things. Dissatisfied always want a change, wants to travel. Persons with a history of tuberculosis in the family ${ }^{[9]}$. If Tuberculinum bovinum be given in $10 \mathrm{M}, 50 \mathrm{M}$ and $\mathrm{cm}$ potencies, two doses of each potency at long intervals all children and young people who have inherited tuberculosis may be inherited from their and resiliency will be restored. It cures most cases of adenoids and tuberculosis glands of the neck ${ }^{[10]}$.

\section{Agraphis Nutans}

Obstruction of the nostrils from adenoids. Throat deafness one of the leading remedies in Adenoids ${ }^{[14]}$. Dr. Cooper gives "Adenoids with enlarged tonsils; frequently accompanying dentition". Much clear mucus discharge ${ }^{[17]}$.

\section{Calcarea Carb}

Swelling of tonsils, difficulty swallowing. Stoppage of nose in morning on rising. Offensive odour of the nose as from and eggs. Takes cold at every change of weather ${ }^{[12]}$. Obstinate children are self-willed. Dull lethargic children who don't want to play. Complaints of teething children, fair plump children, big head and big belly. ${ }^{(9)}$ Great longing for boiled eggs, raw potatoes and flour great aversion to meat, defective dentition in children, very slow in teething, scrofulous children constant subject to sour diarrhoea, profuse perspiration over the head, tendency to obesity with pot belliedness. A barometer indicating scrofulous diathesis ${ }^{[11]}$. Pt is generally better when constipated ${ }^{[13]}$.

\section{Calcarea Phos}

Thin children, large, pale tonsils, Calc. ph. 3x, gr. iv. - 30, $8 \mathrm{~h}^{[17]}$.

\section{Bacillinum}

In children with consumptive family history, Bac. 100, gl. v. once a week $^{[17]}$.

\section{Baryta Carb}

Srofulous condition in children, dwarfish children, Aversion to strangers, deficient memory (children cannot remember and learn), salivation, saliva runs out during sleep ${ }^{[14]}$. Liability to tonsilitis after every slight cold or suppressed foot sweat. Disposition to acute tonsilitis with suppuration. Inflammation of cellular membranes of fauces and tonsils with fever, difficult swallowing and speaking, throat is pale, inflammed and enlarged tonsils ${ }^{[15]}$. Inability to swallow anything but liquids ${ }^{[16]}$.

\section{Sulphur}

Children who are always hungry, irritable skins, averse to be washed, Sul. 30, 8h ${ }^{[17]}$

\section{Thuja}

Swelling of tonsils and throat. Painful swallowing and empty swallowing or that of saliva. Blowing from the nose of a large quantity of thick green mucus mixed with blood; later of dry brown scales with mucus which comes from the frontal sinuses and firmly adheres to the swollen upper portion of the nostrils. Accumulation of mucus in posterior nares ${ }^{[14]}$.

\section{Rubric in different Repertories with number of medicines indicated: ${ }^{[18]}$}

[c][Hearing]Impaired; Adenoids, from (see enlarged tonsils): (0)

[c] [Hearing] Impaired; Enlarged tonsils, adenoids with: (18)

[c] [Hearing] Lost; Throat deafness (see nose, adenoids): (0) [c][Nose] Adenoids: (63)

[c][Nose] obstruction; Breathes through mouth; Adenoids, removal after: (1)

[c][Throat] Adenoids (see nose, adenoids): (0)

[c][Throat]; Swelling, Adenoids: (8)

[c][Respiration] snoring; Adenoids removal, after: (1)

[c][Generalities] Adenoids, complaints after removal of: (1)

[BR][Ear]Deafness, hardness of hearing; cause; adenoids and hypertrophied tonsils: (7)

[BR][Throat] Adenoid vegetations: (15)

[BG][Mouth and Throat] Adenoids: (5)

[Cl][Clinical]Adenoids: (9)

[Cl][Clinical] Post-nasal growth; see adenoids: (0)

[PH][Phatak A-Z]Adenoids: (7) 
[PH][Phatak A-Z] Hearing; bad, deafness,impaired; Adenoids from: (1)

[PH][Phatak A-Z] nose; obstructed; breathes through mouth; Adenoids, removal, after: (1)

$[\mathrm{PH}][$ Phatak A-Z]Respiration; Snoring; Adenoids, removal, after: (1)

[SP] [Bio-chemic] Adenoids: (4)

\section{Conclusion}

Adenoids have a significant effect on expressions of face, malocclusion and breathing mode. Therefore, our primary goal is to promote proper nasal respiration throughout a child's early years of facial growth which will prevent many psycho social problems later in life. Homeopathic medicines strengthen the body's own restorative processes, making it strong enough to fight disease.

\section{References}

1. Dhingra PL, Shruti Dhingra, Assisted by Deeksha Dhingra, Diseases of Ear, nose \& throat and head and neck surgery, $7^{\text {th }}$ edition, Elsevier India 2017, 275-276.

2. Logan Turner's Diseases of the Nose, Throat and Ear, Edited by AGD Moran, $10^{\text {th }}$ edition, Elsevier Newyork, 1988, Reprinted 2000.

3. Ramanjaneyulu P. Diseases of the Ear, nose and Throat, $3^{\text {rd }}$ edition 2002.

4. Bhargava KB, Bhargava SK, Shah TM, A short book of ENT diseases, $10^{\text {th }}$ edition, Usha Publications 2014.

5. https://my.clevelandclinic.org/health/treatments/15447adenoidectomy-adenoid-removal

6. https://blog.ekincare.com/2019/07/31/adenoid/

7. http://orthodonticreviews.blogspot.com/2012/04/newideas-for-treatment-of-adenoid.html. Chakraborty PK, Chatterjee N, Sharma PK. Effect of epigea mother tincture in nephrolithiasis.

8. https://www.livescience.com/62448-adenoids.html

9. Frans Vermeulens, Concordant Materia Medica, IBPP, 2001.

10. Kent JT, Lectures on Homoeopathic Materia Medica, B. Jain Publishers 2016.

11. Choudhuri NM. A Study on Materia Medica, B.Jain Publishers 2002.

12. William Boericke, New Manual of Homoeopathic Materia Medica and Repertory,

13. Samuel Hahnemann. Organon of Medicine. Sixth edition. New Delhi, B. Jain Publishers P. Shivaraman, Expanded work on Nash 2004.

14. John Henry Clarke, A dictionary of Practical Materia Medica, $22^{\text {nd }}$ edition, B. Jain publishers 2015.

15. Constantaine Hering, The guiding symptoms of our Materia Medica, $11^{\text {th }}$ edition, B. Jain Publishers 2016.

16. Allen HC. Keynotes arranged and classified, leading remedies of the materia medica added with other leading nosodes and Bowel nosodes, $9^{\text {th }}$ edition, IBPP 2004.

17. http://homeoint.org/books1/clarkeprescriber/a.htm\#ade noids

18. HOMPATH classic software version 8.0

19. Ghai OP, Ghai Essential Pediatrics, $9^{\text {th }}$ edition, CBS publishers and Distributors Pvt Ltd 364.

20. Samuel Hahnemann. Organon of Medicine. Sixth edition. New Delhi, B. Jain Publishers.

21. Allen JH. The Chronic Miasms and Pseudo Psora 1908. 